\title{
Genome-wide analysis of genetic diversity and artificial selection in Large White pigs in Russia
}

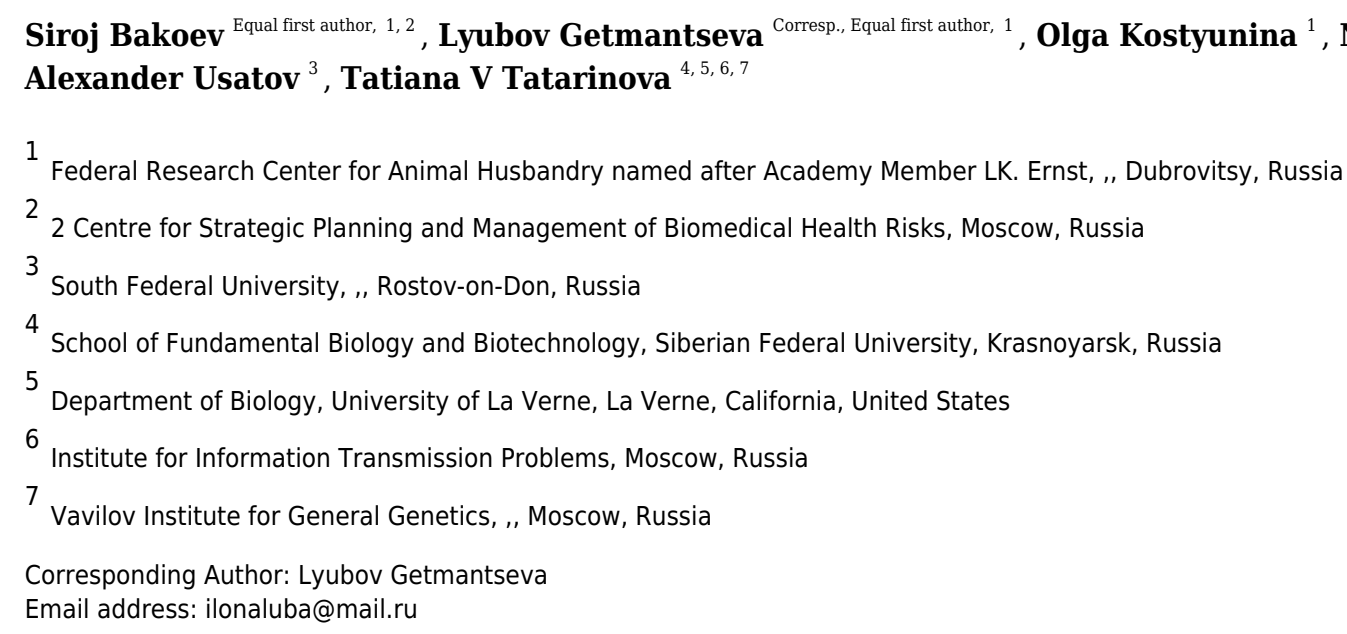

Breeding practices adopted at different farms are aimed at maximizing the profitability of pig farming. In this work, we have analyzed the genetic diversity of Large White pigs in Russia. We compared genomes of historic and modern Large White Russian breeds using 271 pig samples. We have identified 120 candidate regions associated with the differentiation of modern and historic pigs and analyzed genomic differences between the modern farms. The identified genes were associated with height, fitness, conformation, reproductive performance, and meat quality. 


\section{Genome-wide analysis of genetic diversity and 2 artificial selection in Large White pigs in Russia}

3 Siroj Bakoev ${ }^{1,2 \#}$, Lyubov Getmantseva ${ }^{1 * \#,}$, Olga Kostyunina ${ }^{1}$, Nekruz Bakoev ${ }^{1}$, Yuri Prytkov ${ }^{1}$,

4 Alexsander Usatov ${ }^{3}$, Tatiana Tatarinova ${ }^{4-7}$

61 Federal Research Center for Animal Husbandry named after Academy Member LK. Ernst, 7 Dubrovitsy, Russia

82 Centre for Strategic Planning and Management of Biomedical Health Risk, Moscow, Russia

93 South Federal University, Rostov-on-Don, Russia

104 Department of Biology, University of La Verne, La Verne, CA, United States of America

115 Institute for Information Transmission Problems, Russian Academy of Sciences, Moscow, 12 Russia

136 Vavilov Institute for General Genetics, Moscow, Russia

147 School of Fundamental Biology and Biotechnology; Siberian Federal University, Krasnoyarsk, 15 Russia

$16 *$ Corresponding Author: Lyubov Getmantseva ${ }^{1}$

17 Email address: ilonaluba@mail.ru 


\section{Abstract}

20 Breeding practices adopted at different farms are aimed at maximizing the profitability of pig 21 farming. In this work, we have analyzed the genetic diversity of Large White pigs in Russia. We 22 compared genomes of historic and modern Large White Russian breeds using 271 pig samples.

23 We have identified 120 candidate regions associated with the differentiation of modern and historic 24 pigs and analyzed genomic differences between the modern farms. The identified genes were 25 associated with height, fitness, conformation, reproductive performance, and meat quality. 
${ }_{26}$ Introduction

Human consumption drives the artificial selection of farm animals. Understanding how selection creates genetic differences between populations of different farms is essential for effective livestock development.

In the last two centuries, a common strategy was to maximize pig farming profitability of highly productive commercial breeds (such as Large White, Landrace, and Duroc) with high growth rates, good feed conversion and increased lean meat yield (Wang et al., 2018). As a result, these breeds became popular worldwide, including in the Russian Federation (Traspov et al., 2016c,a,b; Čandek-Potokar et al., 2019; Čandek-Potokar \& Nieto, 2019).

Considering that Yorkshire pigs in Northern America are direct descendants of the European Large White lineage (Amer et al., 2020), Large White is the most common commercial breed group. Countries that develop production usually import the breeding stock of Large White pigs since these pigs have a flexible genetic structure adapted to selection pressure (Getmantseva et al., 2020). This flexibility and genetic variation of the breed make it an exciting object for scientists striving to find the genomic regions and genes responsible for the variation.

The initial livestock of Large White pigs (approximately 100 animals) was brought to the Soviet Union from England in 1923. As a result of continuous breeding efforts, a new regional population of the Large White breed was created in the USSR during the second half of the $20^{\text {th }}$ century (Traspov et al., 2016a; Getmantseva et al., 2020). The fall of the Soviet Union caused another period of hardship for Russian pig farming. The breeding programs were nearly stopped, farming practices deteriorated, pigs were massively affected by diseases, and were culled in huge numbers. After the USSR's collapse, the Soviet livestock was almost entirely replaced by imported pigs from the leading breeding centers of Denmark, France, England, Holland, Ireland, etc. Mitochondrial DNA analysis of pigs from various European breeding centers shows significant genetic differences (Getmantseva et al., 2020). In this work, we compare the Large White pigs of Soviet breeding with the modern commercial pigs. We have also analyzed the DNA structure of contemporary Large White pigs within and between the breeding farms in Russia. We have identified selection signatures attributed to the socio-economic conditions and breeding centers' practices. 
${ }_{56}$ Materials and methods

\section{Animals and sample collection}

58

59

60

61

62

63

64

65

66

67

68

69

According to standard monitoring procedures and guidelines, the participating holdings specialists collected tissue samples, following the ethical protocols outlined in the Directive 2010/63/EU (2010). The pig ear samples (ear pluck) were obtained as a general breeding monitoring procedure or during the slaughter. The collection of ear samples is a standard practice in pig breeding (Kunhareang, Zhou \& Hickford, 2010). Previously collected historic tissue samples of the Soviet-bred pigs were obtained from four different farms in Russia between 2006 and 2010. The samples were stored at the Russian Center for Collective Use of Scientific Equipment Bioresources and Bioengineering of Agricultural Animals of the LK Ernst Federal Research Center for Animal Husbandry. They may be the last remaining Soviet-bred pigs.

We have assembled a pool of 271 pig samples; 99 historical examples of the Large White pigs from the Soviet breeding program (LW_Old, samples collected from four breeding farms between 2006 and 2010); 106 samples of Large White pigs of modern breeding from four Russian farms (LW_New: LW_1 $=28 ; \mathrm{LW} \_2=31 ; \mathrm{LW} 33=26 ; \mathrm{LW} \_4=21$, all samples collected between 2018 and 2020). The Landrace $(L=23)$ and Duroc $(D=43)$ samples were collected between 2018 and 2020. Genomic DNA was extracted from ear samples using a DNA-Extran-2 reagent kit (OOO NPF Sintol, Russia) following the manufacturer's protocol. The quantity, quality, and integrity of DNA were assessed using a Qubit 2.0 fluorometer (Invitrogen / Life Technologies, USA) and a NanoDrop8000 spectrophotometer (ThermoFisher Scientific, USA).

\section{Genotyping}

The samples were genotyped using the GeneSeek ${ }^{\circledR}$ GGP Porcine HD Genomic Profiler v1 (Illumina Inc, USA), which includes 68,516 SNPs evenly distributed with an average spacing of $25 \mathrm{~kb}$. Genotype quality control and data filtering were performed using PLINK 1.9, as recommended by (Marees et al., 2018). The total genotyping rate is $0.999307 ; 41,262$ variants and 271 pigs passed the QC filters and were retained for further analysis. 


\section{Data availability}

The dataset can be accessed at http://www.compubioverne.group/data/PIG/.

\section{Population structure analysis}

To study population structure, we performed a singular value decomposition (SVD) decomposition of the GRM using the SVD function in R (Barker et al., 2001; VanRaden, 2008). $\mathrm{R}$ package AdmixTools was used to compute various $\mathrm{F}_{2}$ statistics for all pairs of populations and $\mathrm{F}_{3}$ statistics outgroup statistics estimating the relative divergence time for pairs of populations, using the Duroc pigs as an outgroup (Lazaridis, Patterson \& Reich; Patterson et al., 2012). AdmixTools was also and to plot the trees (Patterson et al., 2012; Liu et al., 2019). Using the find_graphs routine, we have generated and evaluated admixture graphs to find the best-fitting arrangements. Although $\mathrm{F}_{\mathrm{ST}}$ and $\mathrm{F}_{2}$ statistics also calculate genetic distance or divergence time, they may be influenced by population sizes. Statistic $F_{3}$ (outgroup; A, B) estimates the genetic distance between the outgroup and branching point between populations A and B (Maier \& Patterson, 2020).

To study the genetic structure, we used the VanRaden genomic relationship matrix (GRM)) (VanRaden, 2008). This matrix is constructed from the SNP matrix $Z$, where rows correspond to individuals and columns to markers, as $G=\frac{z z^{\prime}}{k}$, where denominator $k$ is calculated using the allele frequencies of genotyped individuals: $k=2 \sum_{i} p_{i}\left(1-p_{i}\right)$. The denominator attains maximum when all allele frequencies are equal to $1 / 2$.

We performed the SVD decomposition of GRM using the SVD function in R. Singular value decomposition (SVD) is a valuable tool for characterizing population genetic structure to detect and extract small signals even if the data is noisy (Berrar, Dubitzky \& Granzow, 2007). Besides, a graphics package in R based on the GRM matrix is used to visualize the relationships between the studied populations of pigs. Plots of the first and second SVD components and a heat map were generated to visualize the SVD results. We used the singular value decomposition (SVD) approach (Golub \& Reinsch, 1971) to assess the genetic structure of the studied populations of Large White pigs in Russia. 
To visualize the relationship between the studied populations of pigs using the graphics

110

111

112

113

114

115

116

117

118

119

120

121

122

123

124

125

126

127

128

129

130

131

132

133

134

135

136

137

package in $\mathrm{R}$, based on the GRM matrix, we built a heatmap plot that has separated the pigs by breeds. (R: A Language and Environment for Statistical Computing, http://www.R-project.org)

\section{Detection of selection signatures}

We used two statistics that can be calculated for unphased genotypic data: $\mathrm{F}_{\mathrm{ST}}$ and $\mathrm{F}_{\mathrm{LK}}$. Fixation index $\mathrm{F}_{\mathrm{ST}}$ is a measure of population differentiation due to genetic structure. It is frequently estimated from genetic polymorphism data, such as single-nucleotide polymorphisms (SNP) or microsatellites. $\mathrm{F}_{\mathrm{ST}}$ value of a locus is calculated as a ratio of the variance of allele frequencies between the populations and the sum of the variances within and between populations. Positive selection is indicated by high $\mathrm{F}_{\mathrm{ST}}$ values relative to their heterozygosity (Weigand \& Leese, 2018). Smoothing of $\mathrm{F}_{\mathrm{ST}}$ is used to identify contiguous genomic regions under selection. The smoothed $\mathrm{F}_{\mathrm{ST}}$ method is based on the pure drift model of Nicholson et al. (2002) (Nicholson et al., 2002). According to this model, individual SNPs are grouped into genomic windows, and their average smoothed $F_{\mathrm{ST}}$ values are calculated. Smoothed $\mathrm{F}_{\mathrm{ST}}$ is useful for analyzing distantly related populations and reveals subtle differences between them (Porto-Neto et al., 2013).

We compared LW_OLD and LW_New groups using the $\mathrm{F}_{\mathrm{ST}}$ analysis to find genomic traces of recent selection resulting from different socio-economic conditions. We compared pigs from different farms to analyze how the selection centers' preferences and breeding practices affect the genomes. Then each farm was compared to the rest of the subgroups combined. SNP regions with smoothed $\mathrm{F}_{\mathrm{ST}}$ values above the $95^{\text {th }}$ quantile indicate positive selection; the gene content of each region was analyzed.

$\mathrm{F}_{\mathrm{LK}}$ is a population differentiation statistic. The calculation incorporates a kinship matrix representing the relationship between populations. $F_{L K}$-based methods are optimally effective when working with closely related populations (Bonhomme et al., 2010; Fariello et al., 2014). The $\mathrm{F}_{\mathrm{LK}}$ test is an extension of the Lewontin and Krakauer (LK) test (Lewontin \& Krakauer, 1973), which takes into account both hierarchical structure between populations and population size heterogeneity by modeling the genetic discrepancy between populations resulting from population drift and division (Bertolini et al., 2018). We used the hapflk software (Gautier, 2015) (https://forge-dga.jouy.inra.fr/projects/hapflk). $\mathrm{F}_{\mathrm{LK}}$ was used to compare the LW_OLD vs. all 
138 LW_New groups. We have estimated the False Discovery Rate (FDR) for SNP identified by $F_{L K}$ 139 and $\mathrm{F}_{\mathrm{ST}}$ using the qvalue package in R (Storey et al., 2020); we assumed the FDR cut-off of 0.15.

\section{Functional analysis}

Ensembl! Annotation of Sus scrofa 11.1, https://www.ensembl.org/index.html was used to analyze genes in the identified regions. Gene set enrichment analysis with Fisher's Exact test was done using the PANTHER database (http:/www.pantherdb.org/). We have also studied the GWAS literature for humans and animals for all identified genes.

\section{Results}

Admixture (Alexander, Novembre \& Lange, 2009) analysis was conducted for $\mathrm{K}=2, \ldots, 20$ (Figure 1). Across all K values, only Duroc, LW_2, and LW_4 were represented by a single admixture component. Even at $\mathrm{K}=2$, the population structure of the Large White pigs is visibly complex, and it can be partitioned into subpopulations that generally agree with the farm of origin. Also, the admixture profiles of modern LW pigs are different from the Soviet-bred LW pigs.

The smallest cross-validation error was obtained for $\mathrm{K}=10$ (Figure S1), and we have used this value in the subsequent calculations. We used Kullback-Leibler distance to partition each population into subpopulations. Large White 2 (LW_2) was a homogeneous population, LW_3 had two subpopulations $(31,17,9)$; Three groups of pigs were partitioned into three subpopulations: Duroc $(17,17,9)$, Landrace $(20,2,1)$, and LW_4 (18, 2, 1); LW_Old were divided into four subpopulations $(36,31,19,13)$. Next, we have applied GPS (Elhaik et al., 2014) to test the assignment accuracy using the leave-one-out validation procedure for subgroups with at least two members: all subpopulation labels were correctly recovered. Therefore, there is a possible lack of genetic continuity between the Soviet and Russian pig breeding and the absence of common breeding standards.

To investigate this further, we computed $\mathrm{F}_{2}$ statistics for all pairs of populations and $\mathrm{F}_{3}$ outgroup statistics, estimating the relative divergence time for pairs of populations, using the Duroc pigs as an outgroup (Table 1). Figure 2 shows the best graph (identified by the find_graphs routine) connecting the studied old and new populations. $F_{3}$ analysis shows that although the 
165 modern Large White pigs differ from farm to farm, they share more with each other and with the 166 old Large White pigs than with the Landrace pigs.

167 We used the singular value decomposition (SVD) approach (Golub \& Reinsch, 1971) to 168 assess the genetic structure of the studied populations of Large White pigs in Russia. Figure 3 (A, 169 B, C) shows the SVD analysis output in axes PC1/PC2, PC1/PC3, and PC2/PC3. Pre-defined $170 \mathrm{breed} /$ farm groups correspond to well-separated clusters. In Figure 3D (Heatmap), all Large White 171 pigs formed a different cluster, separated from the Duroc and Landrace breeds. The same trend 172 can be seen in the PCA plot (Fig. 3A). PCA plots show (Fig. 3C) clear separation of Durok, 173 Landrace, and all Large White breeds. Also, LW pigs from different farms form separate clusters. 174 This result agrees with the admixture, $\mathrm{F}_{2}$, and $\mathrm{F}_{3}$ analyses.

175 Next, we used the smoothed $\mathrm{F}_{\mathrm{ST}}$ and the $\mathrm{F}_{\mathrm{LK}}$ to compare the modern and historic Russian 176 pig populations. There were 120 genes associated with the differentiation between old and new 177 Large White breeds: 52 were identified by the $\mathrm{F}_{\mathrm{ST}}$ method and 68 by the $\mathrm{F}_{\mathrm{LK}}$ method; both 178 approaches flagged 16 genes.

$179 \quad \mathrm{~F}_{\mathrm{ST}}$ analysis has identified several genomic regions. Chr1: $51753405-51918328$ (4 SNPs), 180 Chr4: 81493481-83928709 (29 SNPs), Chr4: 127146360-128244327 (23 SNPs), Chr5: 7147061181 72783062 (36 SNPs), Chr6: $45595002-45854092$ (7 SNPs) and Chr6: 106647339-121553230 (95 SNPs) (Supp. Table 1). According to the $\mathrm{F}_{\mathrm{LK}}$ method with the most significant signals, 158 SNPs were identified (Figure 4, Supp. Table 3), of which 27 SNPs on Chr6: 107577819-12095419 were also determined by the $\mathrm{F}_{\mathrm{ST}}$ method.

After determining the overlap of the identified SNPs with the known QTLs, we have found that despite producing different SNP lists, $\mathrm{F}_{\mathrm{ST}}$ and the $\mathrm{F}_{\mathrm{LK}}$ methods have resulted in nearly identical QTLs lists. According to either method, the identified areas overlap with quantitative trait loci (QTLs) for traits related to meat and anatomical characteristics, animal fitness, meat color, meat quality, conformation indicators of pigs, defects, susceptibility to diseases, blood biochemistry, 190 reproductive traits (fertility and reproductive organs), and productivity traits (growth and development) (Supp. Table 2).

Based on the pathway enrichment analysis, nine significant pathways were identified by $\mathrm{F}_{\mathrm{ST}}$ (Table 2). The genes detected by both approaches belong to six pathways: Synaptic vesicle trafficking (regulates the processes of the nervous system), T-cell activation (ensures the 
196 for brain function and behavior), Muscarinic acetylcholine receptor 1 and 3 signaling pathway 197 (participates in the peripheral nervous system, controls parasympathetic reactions), PDGF 198 signaling pathway (responsible for the structural and functional development of the body), and 199 Gonadotropin-releasing hormone receptor pathway (controls reproductive function).

200 Genomic signatures of different breeding practices were analyzed by comparing subgroups 201 from the LW_New group using the smoothed $F_{\text {ST }}$ (Table 3). In pigs LW_1, a strong signal was 202 detected on Chr14: 45509383-46738288 (24 SNPs) (Supp Table 5). This region contains 21 QTLs, 20317 of which are associated with reproductive traits (twelve QTLs - Number of mummified pigs, 204 four QTLs - Litter size, and one QTL - Litter weight total) (Supp Table 6). Also, there are three 205 QTLs for production traits ("Ratio of lifetime non-productive days to herd life" and "Bodyweight 206 at birth") and 1 QTL Health trait ("White blood cell number"). In this region, seven genes were 207 identified (AP1B1, EWSR1, KREMEN1, NEFH, THOC5, TTC28, ZNRF3) (Supp Table 5). The 208 enrichment analysis has identified the Wnt signaling pathway involved in regulating embryonic 209 development (Table 4).

210 In LW_2, signals were found on Chr1: 62307146-66047984 (70 SNPs) (Supp Table 7).

211 This area overlaps with 5 QTLs: Reproductive traits (Litter size), Exterior traits (Behavioral and 212 Body shape), and Meat and carcass traits (Palmitic acid content and Ham weight) (Supp Table 8). 213 In this region, nine genes were identified (FBXL4, FHL5, GPR63, KLHL32, MANEA, MMS22L, 214 POU3F2, U6, UFL1) (Supp Table 7). No known pathways were significantly enriched.

In LW_3, signals were found on SSC6: 130871443-133500969 (44 SNPs) and SSC15:

216 77070266-77566996 (Supp Table 9). These areas overlap with 89 QTLs, of which 85 QTLs are 217 associated with Meat and carcass traits (of which 68 QTLs are responsible for Conductivity 45 218 minutes post-mortem) (Supp Table 10). 4 genes were identified in this region (ADGRL2, 219 GORASP2, METTL8, TLK1) (Supp Table 9). The gene GORASP2 was also identified in strong 220 outliers, determined by the $\mathrm{F}_{\mathrm{LK}}$ LW_Old vs. LW_New method. No known pathways were 221 significantly enriched.

222 In LW_4, signals were found on Chr 4: 123920076-125079457 (24 SNPs), 6: 1973066222320040749 (13 SNPs) and Chr 9: $74428112-76248997$ (32 SNPs) (Supp Table 11). These areas 224 overlap with four QTLs: Reproduction traits (Corpus luteum number and Teat number) and Meat 225 and carcass traits (Intramuscular fat content and Conductivity 45 minutes post-mortem) (Supp 226 Table 16). In this area, 21 genes were identified, one of which $A S B 4$ was also identified in the area 
227 of strong outliers, based on the comparison of old and new pigs (Supp Table 11). No known

228 pathways were significantly enriched.

\section{Discussion}

230

231

232

233

234

235

236

237

238

239

240

241

242

243

244

245

246

247

248

249

250

251

252

253

254

255

In nature, individuals with the highest fitness tend to have more offspring, increasing favorable alleles in the population and leaving traces in genomes. These signatures of selection can be used to identify genomic regions under selection pressure (Getmantseva et al., 2020). The mechanisms underlying phenotypic differentiation induced by pig breeding have been investigated using genome-wide genotype data or high throughput sequencing (Groenen et al., 2012; Yang et al., 2014; Diao et al., 2018; Gurgul et al., 2018; Xu et al., 2020b,a; Bovo et al., 2020). Genomic loci associated with growth traits, reproductive traits, coat color, ear shape, and other phenotypes are now known, as well as the genes that influence these traits (Wilkinson et al., 2013; Zhang et al., 2018; Yu et al., 2020). We compared the Large White pigs of Russian breeding (LW_Old) and modern commercial pigs ( $\mathrm{LW} \_$New) in this work. We have identified 120 genes (52 by the $\mathrm{F}_{\mathrm{ST}}$ method and 68 by the $\mathrm{F}_{\mathrm{LK}}$ method, and 16 genes by both methods) in genomic regions associated with the differentiation of LW_OLD and LW_NEW pigs.

Gene CNTN1 (SSC5) is a member of the neural immunoglobulin (Ig) subfamily and is involved in the formation of axonal connections in the developing nervous system (Wang et al., 2019). In vertebrates, the contactin family (CNTN) includes six related cell adhesion molecules participating in the nervous system formation and maintenance and in building neural circuits. CNTN genes are associated with an increased risk for autism (Lin et al., 2016). Also, genes associated with neural processes are often represented in the genomic regions associated with animals' domestication (Alberto et al., 2018). The B4GALT6 (SSC6) gene encodes lactosylceramide synthase, an essential enzyme for the biosynthesis of glycolipids. The GAREM1 gene (SSC6) encodes an adapter protein that functions in a signaling pathway mediated by the epidermal growth factor (EGF) receptor. B4GALT6 and GAREM1 are likely responsible for cardiac abnormalities, causing pigs to die during transportation (Zurbrigg, 2013; Zurbrigg et al., 2017).

The FHOD3 and DTNA genes are considered candidate genes associated with hypertrophic cardiomyopathy, a heart disease that affects all age groups (Liu Y., Li Z., Guo X., 
256 Jing X., Zhang X., Shao H., Guan Y., Abraham M. R., 2017; Zhou Qing et al., 2017), being the 257 most common cause of heart failure and sudden death. FHOD3 gene plays a role in the 258 polymerization of actin filaments in cardiomyocytes, while DTNA belongs to the dystrobrevin

259

260

261

262

263

264

265

266

267

268

269

270

271

272

273

274

275

276

277

278

279

280

281

282

283

284

285

286

subfamily and the dystrophin family. Lack of dystrophin causes Duchenne muscular dystrophy and Becker muscular dystrophy (Tsoumpra et al., 2020). In pigs, dystrophin gene SNPs are associated with alterations in the accumulation of the dystrophin protein in skeletal muscle. It is related to sudden death caused by stress (Joshua T. Selsby, Jason W. Ross, Dan Nonneman, Katrin Hollinger, 2015).

The MPZL1 (SSC4) gene, also known as PZR, is a cell surface glycoprotein belonging to the immunoglobulin superfamily (Jia et al., 2014). In studies by An et al. (An et al., 2020), the MPZL1 gene was identified as a candidate gene for growth in Simmental beef cattle.

Modern pigs of the Large White breed, relative to pigs of the Soviet breeding program, are distinguished by a high growth rate, good feed conversion, and a smaller fat thickness. They are used in the breeding system as a mother breed and are highly fertile. The affected loci are responsible for productive traits (growth, feed conversion), fitness (fat content and percentage), reproductive traits (number of piglets at birth, multiple births, nest weight at birth). However, based on the results obtained, it can be noted that significant genetic differentiation between the study groups is due to changes in the loci responsible for the quality of meat. Over the past decades, the efforts of commercial pig breeders to increase production efficiency by accelerating animals' growth and development have led to a decrease in the quality indicators and technological properties of meat. These changes were mainly reflected in the content of intramuscular fat and the composition of fatty acids. These indicators determine muscle color, texture, water retention capacity, and the nutritional value of meat.

We have detected signals in areas responsible for animals' brain and nervous system functions and behavioral characteristics. We hypothesize that it may be due to the artificial selection of well-behaved, obedient animals for breeding.

The study of the modern livestock of Large White pigs, stratified by the selection centers, made it possible to identify individual characteristics in each subgroup. In LW_1, the signatures of modern artificial selection were identified in the genome regions mainly responsible for reproductive traits. QTLs for the number of mummified piglets were overrepresented in this area. We speculate that intensive breeding practices aimed to increase the saws' fertility can serve as

Peer) reviewing PDF | (2021:01:57586:1:2:CHECK 7 May 2021) 
287 one reason for mummified piglets since the limited volume of the uterus can lead to embryonic 288 death during days 30 - 115 of fetal development. LW_ 2 shows a signal in the area associated with 289 a complex of traits responsible for Litter Size and quality, Behavioral, Fatty acid content, 290 Anatomy, and Conformation. LW_3 breeding efforts were focused on meat properties, such as 291 Conductivity 45 minutes post-mortem, Back Fat, Ham and Loin weight, Dressing, Lean meat, and

292

293 294

295 296

297

298 299

300

301

302

303

304

305

306

307

308

309

310

311

muscle protein percentage. Signatures of artificial selection in LW_4 were evident in Corpus luteum number, Teat number, Intramuscular fat content, and Conductivity 45 minutes postmortem.

Since the same phenotype can result from multiple genotypes, similar breeding strategies can result in the same phenotype but different genotypes. Our results suggested that the main emphasis in selecting modern Large White pigs is aimed at productive characteristics, quality, and technological parameters of meat. This hypothesis can be further tested when a larger sample becomes available.

\section{Conclusions}

To identify the putative areas under selection associated with prevailing trends in various socioeconomic conditions and the specific practices and preferences of selection centers, we compared large white pigs of USSR selection and modern Russian commercial livestock. As a result, we found possible selection signals related to traits of height, fitness, conformation, reproductive performance, and meat quality and suggested genes that may act as candidate genes for these traits. These regions can be carefully tested using a larger set of pig samples. We have also identified possible genetic discontinuity between the Soviet-bred and modern Russian pigs.

\section{Funding}

This research was supported by the Russian Science Foundation (RSF) Project No.19-1600109 (genotyping of Large White pigs) and the Russian Science Foundation 19-76-10012 (genotyping of Landrace and Duroc pigs). 


\section{References}

Alberto FJ, Boyer F, Orozco-terWengel P, Streeter I, Servin B, de Villemereuil P, Benjelloun B, Librado P, Biscarini F, Colli L, Barbato M, Zamani W, Alberti A, Engelen S, Stella A, 
Crepaldi P, AdaptMap consortium. 2018. Signatures of selection and environmental adaptation across the goat genome post-domestication. Genetics, selection, evolution: GSE 50:57.

Bonhomme M, Chevalet C, Servin B, Boitard S, Abdallah J, Blott S, Sancristobal M. 2010. Detecting selection in population trees: the Lewontin and Krakauer test extended. Genetics 186:241-262.

Bovo S, Ribani A, Muñoz M, Alves E, Araujo JP, Bozzi R, Čandek-Potokar M, Charneca R, Di Palma F, Etherington G, Fernandez AI, García F, García-Casco J, Karolyi D, Gallo M, Margeta V, Martins JM, Mercat MJ, Moscatelli G, Núñez Y, Quintanilla R, Radović Č, Razmaite V, Riquet J, Savić R, Schiavo G, Usai G, Utzeri VJ, Zimmer C, Ovilo C, Fontanesi L. 2020. Whole-genome sequencing of European autochthonous and commercial pig breeds allows the detection of signatures of selection for adaptation of genetic resources to different breeding and production systems. Genetics, selection, evolution: GSE 52:33.

Čandek-Potokar M, Lukač NB, Tomažin U, Škrlep M, Nieto R. 2019. Analytical Review of Productive Performance of Local Pig Breeds. European Local Pig Breeds - Diversity and Performance. A study of project TREASURE. DOI: 10.5772/intechopen.84214.

Čandek-Potokar M, Nieto R. 2019. European Local Pig Breeds - Diversity and Performance: A study of project TREASURE. BoD - Books on Demand.

Diao S-Q, Yuan-yu LUO, Yun-long MA, Deng X, Ying-ting HE, Ning GAO, Zhang H, Jia-qi LI, Chen Z-M, Zhang Z. 2018. Genome-wide detection of selective signatures in a Duroc pig population. Journal of Integrative Agriculture 17:2528-2535. DOI: 10.1016/s20953119(18)61984-7. 
358 Elhaik E, Tatarinova T, Chebotarev D, Piras IS, Maria Calò C, De Montis A, Atzori M, Marini

359 M, Tofanelli S, Francalacci P, Pagani L, Tyler-Smith C, Xue Y, Cucca F, Schurr TG, Gaieski JB, Melendez C, Vilar MG, Owings AC, Gómez R, Fujita R, Santos FR, Comas D, Balanovsky O, Balanovska E, Zalloua P, Soodyall H, Pitchappan R, Ganeshprasad A,

Hammer M, Matisoo-Smith L, Wells RS, Genographic Consortium. 2014. Geographic population structure analysis of worldwide human populations infers their biogeographical origins. Nature communications 5:3513.

Fariello M-I, Servin B, Tosser-Klopp G, Rupp R, Moreno C, International Sheep Genomics Consortium, San Cristobal M, Boitard S. 2014. Selection signatures in worldwide sheep populations. PloS one 9:e103813.

Gautier M. 2015. Genome-Wide Scan for Adaptive Divergence and Association with Population-Specific Covariates. Genetics 201:1555-1579.

Getmantseva L, Bakoev S, Bakoev N, Karpushkina T, Kostyunina O. 2020. Mitochondrial DNA Diversity in Large White Pigs in Russia. Animals : an open access journal from MDPI 10. DOI: $10.3390 /$ ani10081365.

Golub GH, Reinsch C. 1971. Singular Value Decomposition and Least Squares Solutions. In: Wilkinson JH, Reinsch C, Bauer FL eds. Linear Algebra. Berlin, Heidelberg: Springer Berlin Heidelberg, 134-151.

Groenen MAM, Archibald AL, Uenishi H, Tuggle CK, Takeuchi Y, Rothschild MF, RogelGaillard C, Park C, Milan D, Megens H-J, Li S, Larkin DM, Kim H, Frantz LAF, Caccamo M, Ahn H, Aken BL, Anselmo A, Anthon C, Auvil L, Badaoui B, Beattie CW, Bendixen C, Berman D, Blecha F, Blomberg J, Bolund L, Bosse M, Botti S, Bujie Z, Bystrom M, Capitanu B, Carvalho-Silva D, Chardon P, Chen C, Cheng R, Choi S-H, 
Chow W, Clark RC, Clee C, Crooijmans RPMA, Dawson HD, Dehais P, De Sapio F, Dibbits B, Drou N, Du Z-Q, Eversole K, Fadista J, Fairley S, Faraut T, Faulkner GJ, Fowler KE, Fredholm M, Fritz E, Gilbert JGR, Giuffra E, Gorodkin J, Griffin DK, Harrow JL, Hayward A, Howe K, Hu Z-L, Humphray SJ, Hunt T, Hornshøj H, Jeon J-T, Jern P, Jones M, Jurka J, Kanamori H, Kapetanovic R, Kim J, Kim J-H, Kim K-W, Kim T-H, Larson G, Lee K, Lee K-T, Leggett R, Lewin HA, Li Y, Liu W, Loveland JE, Lu Y, Lunney JK, Ma J, Madsen O, Mann K, Matthews L, McLaren S, Morozumi T, Murtaugh MP, Narayan J, Nguyen DT, Ni P, Oh S-J, Onteru S, Panitz F, Park E-W, Park H-S, Pascal G, Paudel Y, Perez-Enciso M, Ramirez-Gonzalez R, Reecy JM, Rodriguez-Zas S, Rohrer GA, Rund L, Sang Y, Schachtschneider K, Schraiber JG, Schwartz J, Scobie L, Scott C, Searle S, Servin B, Southey BR, Sperber G, Stadler P, Sweedler JV, Tafer H, Thomsen B, Wali R, Wang J, Wang J, White S, Xu X, Yerle M, Zhang G, Zhang J, Zhang J, Zhao S, Rogers J, Churcher C, Schook LB. 2012. Analyses of pig genomes provide insight into porcine demography and evolution. Nature 491:393-398.

Gurgul A, Jasielczuk I, Ropka-Molik K, Semik-Gurgul E, Pawlina-Tyszko K, Szmatoła T, Szyndler-Nędza M, Bugno-Poniewierska M, Blicharski T, Szulc K, Skrzypczak E, Krupiński J. 2018. A genome-wide detection of selection signatures in conserved and commercial pig breeds maintained in Poland. BMC genetics 19:95.

Jia D, Jing Y, Zhang Z, Liu L, Ding J, Zhao F, Ge C, Wang Q, Chen T, Yao M, Li J, Gu J, He X. 2014. Amplification of MPZL1/PZR promotes tumor cell migration through Srcmediated phosphorylation of cortactin in hepatocellular carcinoma. Cell research 24:204-217.

Joshua T. Selsby, Jason W. Ross, Dan Nonneman, Katrin Hollinger. 2015. Porcine Models of 
404 405

406

407

408

409

410

411

412

413

414

415

416

417

418

419

420

421

422

423

424

425

426

Muscular Dystrophy. ILAR journal / National Research Council, Institute of Laboratory Animal Resources 56:116-126.

Kunhareang S, Zhou H, Hickford JGH. 2010. Rapid DNA extraction of pig ear tissues. Meat science 85:589-590.

Lazaridis I, Patterson N, Reich D. Admixture Graph Modeling. Ancient human genomes suggest three ancestral populations for present-day Europeans:91.

Lewontin RC, Krakauer J. 1973. Distribution of gene frequency as a test of the theory of the selective neutrality of polymorphisms. Genetics 74:175-195.

Lin Y-C, Frei JA, Kilander MBC, Shen W, Blatt GJ. 2016. A Subset of Autism-Associated Genes Regulate the Structural Stability of Neurons. Frontiers in cellular neuroscience 10:263.

Liu L, Bosse M, Megens H-J, Frantz LAF, Lee Y-L, Irving-Pease EK, Narayan G, Groenen MAM, Madsen O. 2019. Genomic analysis on pygmy hog reveals extensive interbreeding during wild boar expansion. Nature communications 10:1992.

Liu Y., Li Z., Guo X., Jing X., Zhang X., Shao H., Guan Y., Abraham M. R. 2017. Recent Advances in Hypertrophic Cardiomyopathy: A System Review. In: Genetic Polymorphisms. Intechopen,.

Maier R, Patterson N. 2020. ADMIXTOOLS 2.

Marees AT, de Kluiver H, Stringer S, Vorspan F, Curis E, Marie-Claire C, Derks EM. 2018. A tutorial on conducting genome-wide association studies: Quality control and statistical analysis. International journal of methods in psychiatric research 27:e1608.

Nicholson G, Smith AV, Jonsson F, Gustafsson O, Stefansson K, Donnelly P. 2002. Assessing population differentiation and isolation from single-nucleotide polymorphism data. 
427

428

429

430

431

432

433

434

435

436

437

438

439

440

441

442

443

444

445

446

447

448

449

Journal of the Royal Statistical Society: Series B (Statistical Methodology) 64:695-715. DOI: $10.1111 / 1467-9868.00357$.

Patterson N, Moorjani P, Luo Y, Mallick S, Rohland N, Zhan Y, Genschoreck T, Webster T, Reich D. 2012. Ancient admixture in human history. Genetics 192:1065-1093.

Porto-Neto LR, Sonstegard TS, Liu GE, Bickhart DM, Da Silva MVB, Machado MA, Utsunomiya YT, Garcia JF, Gondro C, Van Tassell CP. 2013. Genomic divergence of zebu and taurine cattle identified through high-density SNP genotyping. BMC genomics $14: 876$.

Smith JL. 2014. Agricultural Involution in the Postwar Soviet Union. International Labor and Working-Class History. JSTOR 85:59-74.

Storey JD, Bass AJ, Dabney A, Robinson D. 2020. qvalue: Q-value estimation for false discovery rate control.

Traspov A, Deng W, Kostyunina O, Ji J, Shatokhin K, Lugovoy S, Zinovieva N, Yang B, Huang L. 2016a. Erratum to: Population structure and genome characterization of local pig breeds in Russia, Belorussia, Kazakhstan and Ukraine. Genetics Selection Evolution 48. DOI: $10.1186 / \mathrm{s} 12711-016-0235-8$.

Traspov A, Deng W, Kostyunina O, Ji J, Shatokhin K, Lugovoy S, Zinovieva N, Yang B, Huang L. 2016b. Population structure and genome characterization of local pig breeds in Russia, Belorussia, Kazakhstan and Ukraine. Genetics Selection Evolution 48. DOI: 10.1186/s12711-016-0196-y.

Traspov AA, Kostyunina OV, Domsky IA, Ekonomov AV, Sermyagin AA, Zinovieva NA. 2016c. 1742 Studing of population structure of European wild boar (Sus scrofa) and its subspecies, inhabiting Russia. Journal of Animal Science 94:848-849. DOI: 
451

452

453

454

455

456

457

458

459

460

461

462

463

464

465

466

467

468

469

470

471

472

Tsoumpra MK, Sawatsubashi S, Imamura M, Fukumoto S, Takeda S, Matsumoto T, Aoki Y. 2020. Dystrobrevin alpha gene is a direct target of the vitamin D receptor in muscle. Journal of molecular endocrinology 64:195-208.

VanRaden PM. 2008. Efficient methods to compute genomic predictions. Journal of dairy science 91:4414-4423.

Wang L-J, Wu C-C, Lee M-J, Chou M-C, Lee S-Y, Chou W-J. 2019. Peripheral Brain-Derived Neurotrophic Factor and Contactin-1 Levels in Patients with AttentionDeficit/Hyperactivity Disorder. Journal of clinical medicine research 8. DOI: $10.3390 /$ jcm8091366.

Wang K, Wu P, Yang Q, Chen D, Zhou J, Jiang A, Ma J, Tang Q, Xiao W, Jiang Y, Zhu L, Li X, Tang G. 2018. Detection of Selection Signatures in Chinese Landrace and Yorkshire Pigs Based on Genotyping-by-Sequencing Data. Frontiers in genetics 9:119.

Weigand H, Leese F. 2018. Detecting signatures of positive selection in non-model species using genomic data. Zoological journal of the Linnean Society 184:528-583.

Wilkinson S, Lu ZH, Megens H-J, Archibald AL, Haley C, Jackson IJ, Groenen MAM, Crooijmans RPMA, Ogden R, Wiener P. 2013. Signatures of diversifying selection in European pig breeds. PLoS genetics 9:e1003453.

Xu Z, Sun H, Zhang Z, Zhao Q-B, Olasege BS, Qiu-meng L, Yue Y, Ma P-P, Zhang X-Z, Wang Q-S, Pan Y-C. 2020a. Genome-wide detection of selective signatures in a Jinhua pig population. Journal of integrative agriculture 19:1314-1322.

Xu Z, Zhong XU, Hao SUN, Zhang Z, Zhao Q-B, Olasege BS, Qiu-meng L, Yang YUE, Pei-pei MA, Zhang X-Z, Wang Q-S, Yu-chun PAN. 2020b. Genome-wide detection of selective 
signatures in a Jinhua pig population. Journal of Integrative Agriculture 19:1314-1322.

474 DOI: $10.1016 / \mathrm{s} 2095-3119(19) 62833-9$.

475

476

477

478

479

480

481

482

483

484

485

486

487

488

489

490

491

Yang S, Li X, Li K, Fan B, Tang Z. 2014. A genome-wide scan for signatures of selection in Chinese indigenous and commercial pig breeds. BMC genetics 15:7.

Yu J, Zhao P, Zheng X, Zhou L, Wang C, Liu J-F. 2020. Genome-Wide Detection of Selection Signatures in Duroc Revealed Candidate Genes Relating to Growth and Meat Quality. G3 10:3765-3773.

Zhang Z, Xiao Q, Zhang Q-Q, Sun H, Chen J-C, Li Z-C, Xue M, Ma P-P, Yang H-J, Xu N-Y, Wang Q-S, Pan Y-C. 2018. Genomic analysis reveals genes affecting distinct phenotypes among different Chinese and western pig breeds. Scientific reports 8:13352.

Zhou Qing, Wei Si-Si, Wang Hong, Wang Qian, Li Wei, Li Gang, Hou Jian-Wen, Chen XiaoMeng, Chen Jie, Xu Wei-Ping, Li Yi-Gang, Wang Yue-Peng. 2017. Crucial Role of ROCK2-Mediated Phosphorylation and Upregulation of FHOD3 in the Pathogenesis of Angiotensin II-Induced Cardiac Hypertrophy. Hypertension 69:1070-1083.

Zurbrigg K. 2013. Testing for a genetic defect in the hearts of pigs that die in transit to the abattoir.

Zurbrigg K, van Dreumel T, Rothschild MF, Alves D, Friendship R, O'Sullivan T. 2017. Piglevel risk factors for in-transit losses in swine: a review. Canadian journal of animal science. DOI: 10.1139/cjas-2016-0193. 


\section{Table $\mathbf{1}$ (on next page)}

Table 1. F3 outgroup analysis.

F3 outgoup statistics for all breeds was calculated using the Admixtoools package in R. 
2 Table 1. F3 outgroup analysis.

\begin{tabular}{|c|c|c|c|c|c|}
\hline A & B & f3 estimate & $\begin{array}{c}\text { Standard } \\
\text { error }\end{array}$ & z-score & p-value \\
\hline LW_1 & LW_2 & 0.090 & $1.78 \mathrm{E}-03$ & 50.82 & $0.00 E+00$ \\
\hline LW_1 & LW_4 & 0.088 & $1.77 \mathrm{E}-03$ & 49.73 & $0.00 \mathrm{E}+00$ \\
\hline LW_2 & LW_4 & 0.088 & $2.43 \mathrm{E}-03$ & 36.08 & 4.35E-285 \\
\hline LW_2 & LW_3 & 0.081 & $2.32 \mathrm{E}-03$ & 35.13 & $2.22 \mathrm{E}-270$ \\
\hline LW_4 & LW_Old & 0.081 & $1.93 \mathrm{E}-03$ & 41.77 & $0.00 E+00$ \\
\hline LW_3 & $\mathrm{LW}_{-} 4$ & 0.080 & $2.23 \mathrm{E}-03$ & 36.03 & $2.76 \mathrm{E}-284$ \\
\hline LW_1 & LW_3 & 0.080 & $1.51 \mathrm{E}-03$ & 52.98 & $0.00 \mathrm{E}+00$ \\
\hline LW_2 & LW_Old & 0.079 & $1.80 \mathrm{E}-03$ & 43.79 & $0.00 \mathrm{E}+00$ \\
\hline LW_1 & LW_Old & 0.078 & $1.21 \mathrm{E}-03$ & 64.29 & $0.00 \mathrm{E}+00$ \\
\hline LW_3 & LW_Old & 0.075 & $1.63 \mathrm{E}-03$ & 45.97 & $0.00 \mathrm{E}+00$ \\
\hline $\mathrm{L}$ & $\mathrm{LW}_{-} 4$ & 0.064 & $2.10 \mathrm{E}-03$ & 30.53 & $1.10 \mathrm{E}-204$ \\
\hline $\mathrm{L}$ & LW_1 & 0.063 & $1.81 \mathrm{E}-03$ & 35.10 & $6.74 \mathrm{E}-270$ \\
\hline $\mathrm{L}$ & LW_3 & 0.063 & $1.60 \mathrm{E}-03$ & 39.64 & $0.00 E+00$ \\
\hline $\mathrm{L}$ & LW_2 & 0.063 & $2.02 \mathrm{E}-03$ & 30.93 & $5.06 \mathrm{E}-210$ \\
\hline $\mathrm{L}$ & LW_Old & 0.061 & $1.54 \mathrm{E}-03$ & 40.00 & $0.00 E+00$ \\
\hline
\end{tabular}




\section{Table 2 (on next page)}

Table. 2 Major gene pathways identified by the $F_{S T}$ method (LW_Old vs. LW_New)

Based on the pathway enrichment analysis, 37 pathways were identified. 
1 Table. 2 Major gene pathways identified by the $F_{S T}$ method ( $W_{-}$Old vs. LW_New)

\begin{tabular}{|l|l|c|c|c|}
\hline$\#$ & PANTHER Pathways & Expected & $\begin{array}{c}\text { Fold } \\
\text { Enrichment }\end{array}$ & $\begin{array}{c}\text { raw P- } \\
\text { value }\end{array}$ \\
\hline 1 & Synaptic vesicle trafficking & 0.07 & 14.95 & $6.67 \mathrm{E}-02$ \\
\hline 2 & $\begin{array}{l}\text { Biosynthesis of purines de novo (De novo purine } \\
\text { biosynthesis) }\end{array}$ & 0.08 & 11.88 & $8.27 \mathrm{E}-02$ \\
\hline 3 & General transcription regulation & 0.09 & 10.78 & $9.06 \mathrm{E}-02$ \\
\hline 4 & $\begin{array}{l}\text { Signaling pathway of muscarinic acetylcholine } \\
\text { receptor 1 and 3 signaling pathway ) }\end{array}$ & 0.14 & 7.24 & $1.31 \mathrm{E}-01$ \\
\hline 5 & $\begin{array}{l}\text { Transcription regulation by the bZIP transcription } \\
\text { factor }\end{array}$ & 0.14 & 7.13 & $1.33 \mathrm{E}-01$ \\
\hline 6 & $\begin{array}{l}\text { Alzheimer disease-amyloid secretase pathway } \\
\text { T cell activation }\end{array}$ & 0.15 & 6.53 & $1.44 \mathrm{E}-01$ \\
\hline 7 & $\begin{array}{l}\text { PDGF signaling pathway } \\
\text { hormone } \\
\text { receptor or pathway) }\end{array}$ & 0.31 & 3.26 & $2.66 \mathrm{E}-01$ \\
\hline 8 & $\begin{array}{l}\text { Path to the receptors of gonadotropin-releasing } \\
\text { hormone }\end{array}$ & 0.54 & 1.87 & $4.17 \mathrm{E}-01$ \\
\hline
\end{tabular}

2 


\section{Table 3 (on next page)}

Table 3: PANTHER pathways identified by the $F_{S T}$ method in pigs from the $L W \_N e w$ group.

Genomic regions under selection for each subgroup from the LW_New group were determined using the smoothed $F_{\text {ST }}$ method. Corresponding pathways were determined using the PANTHER database. 
1 Table 3: PANTHER pathways identified by the $F_{S T}$ method in pigs from the L $W_{-} N e w$ group

\begin{tabular}{|l|l|l|c|c|c|}
\hline No & & PANTHER Pathways & Expected & Fold & raw P- \\
value
\end{tabular}




\section{Table 4 (on next page)}

Main gene pathways identified by the $F_{S T}$ method in pigs from the LW_New group

Based on the enrichment analysis, one pathway was identified in LW_1, LW_2, and LW_3 pigs, while six pathways were identified in LW_4 pigs. 
1 Table 4: Main gene pathways identified by the $F_{s T}$ method in pigs from the $L W \ldots N e w$ group

\begin{tabular}{|l|l|l|c|c|c|}
\hline No & & PANTHER Pathways & Expected & $\begin{array}{c}\text { Fold } \\
\text { Enrichment }\end{array}$ & $\begin{array}{c}\text { raw P- } \\
\text { value }\end{array}$ \\
\hline 1 & LW_1 & Wnt signaling pathway & 0.08 & 11.49 & $8.20 \mathrm{E}-02$ \\
\hline 2 & LW_2 & Unclassified & 6.16 & 1.14 & $1.00 \mathrm{E}-00$ \\
\hline 3 & LW_3 & Unclassified & 3.52 & 1.14 & $1.00 \mathrm{E}-00$ \\
\hline 4 & LW_4 & General transcription regulation & 0.03 & 28.68 & $3.52 \mathrm{E}-02$ \\
\hline 5 & LW_4 & $\begin{array}{l}\text { Transcription regulation by the bZIP } \\
\text { transcription factor }\end{array}$ & 0.05 & 19.12 & $5.19 \mathrm{E}-02$ \\
\hline 6 & LW 4 & Parkinson disease & 0.09 & 11.72 & $8.28 \mathrm{E}-02$ \\
\hline 7 & LW_4 & Cadherin signaling pathway & 0.11 & 9.16 & $1.04 \mathrm{E}-01$ \\
\hline 8 & LW_4 & Huntington disease & 0.14 & 7.12 & $1.32 \mathrm{E}-01$ \\
\hline 9 & LW 4 & Wnt signaling pathway & 0.24 & 4.13 & $2.17 \mathrm{E}-01$ \\
\hline
\end{tabular}

2 
Figure 1

Figure 1. Admixture profiles for $K=2 \ldots 20$.

Pig breeds are designated on the horizontal axis. D - Duroc, L - Landrace, LW_Old - USSR Large White pigs; $L W \_1, L W \_2, L W_{-} 3, L W \_4$ - modern Large White pigs from different farms. Cross-validation analysis shows that $K=10$ has the smallest CV error.

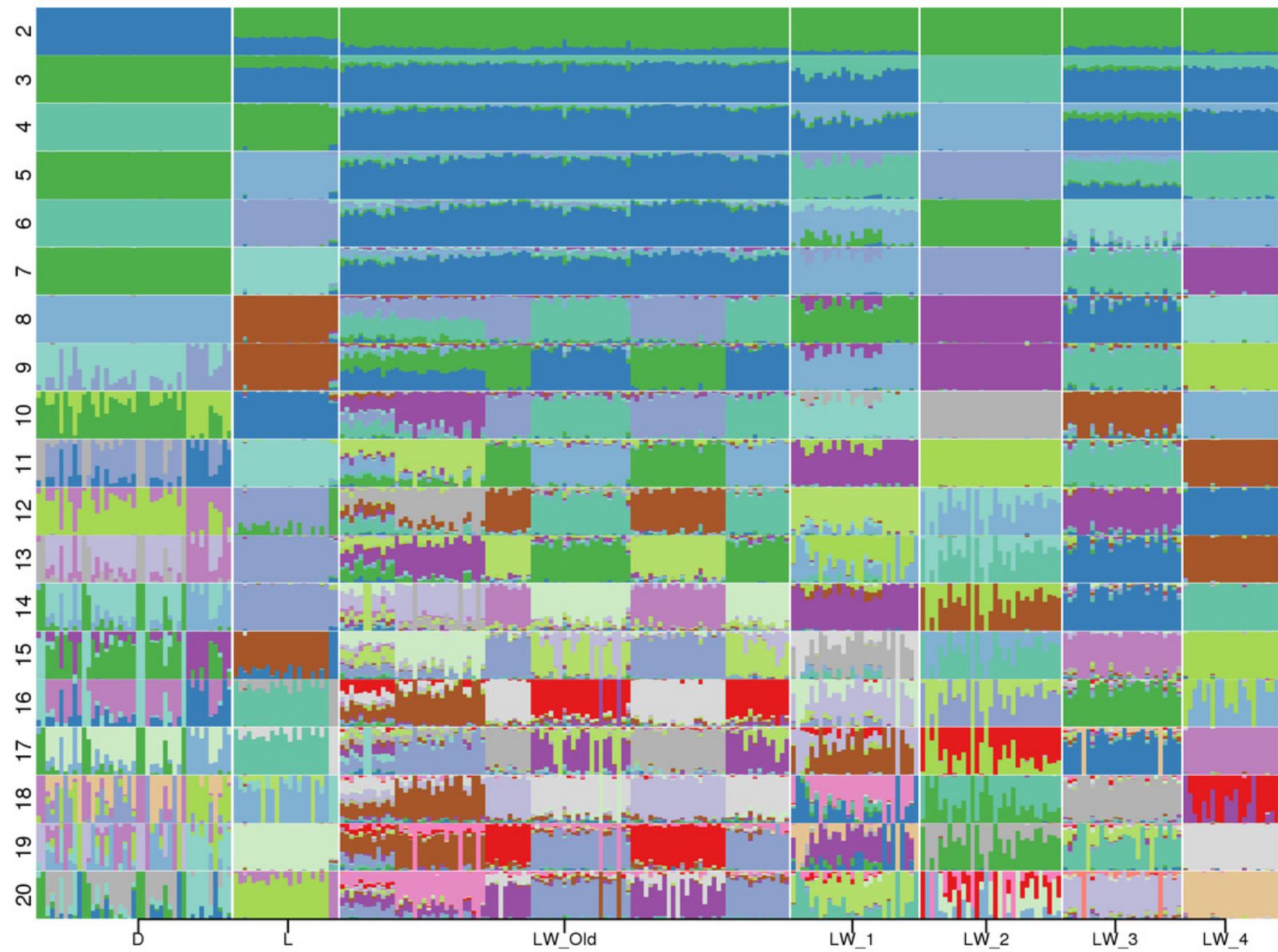


Figure 2

Figure 2. Admixture graph computed using f-statistics.

The plot is done using the ADMIXTOOLS2 R package, using the Duroc pigs as an outgroup.

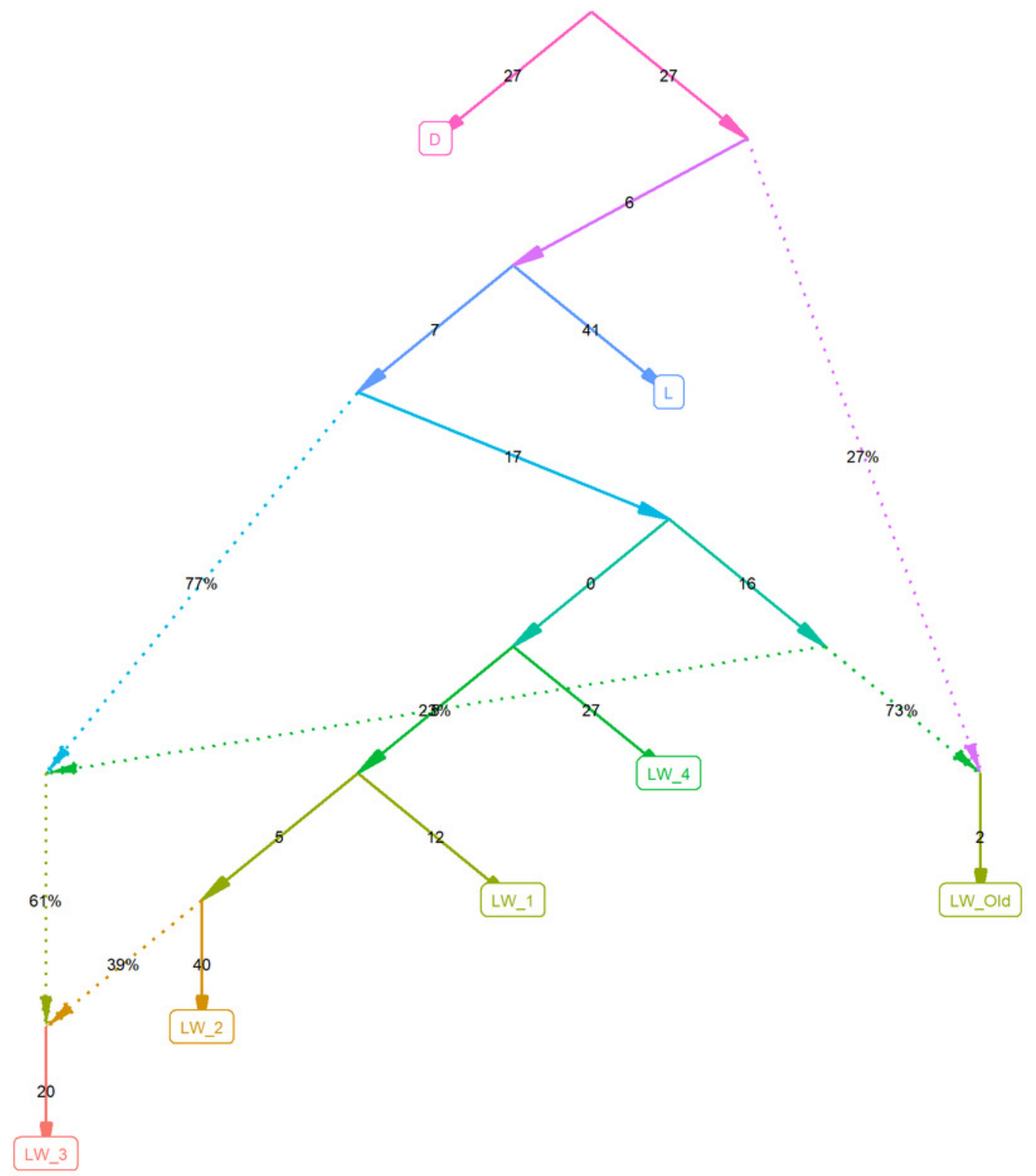


Figure 3

Figure 3. SVD $(a, b, c)$ and Heatmap (d) for pigs.

D - Duroc, L - Landrace, LW_Old - Large White Russian selection, LW-1, 2, 3, 4 - a commercial Large White breed. Each LW group corresponds to a different breeding farm.

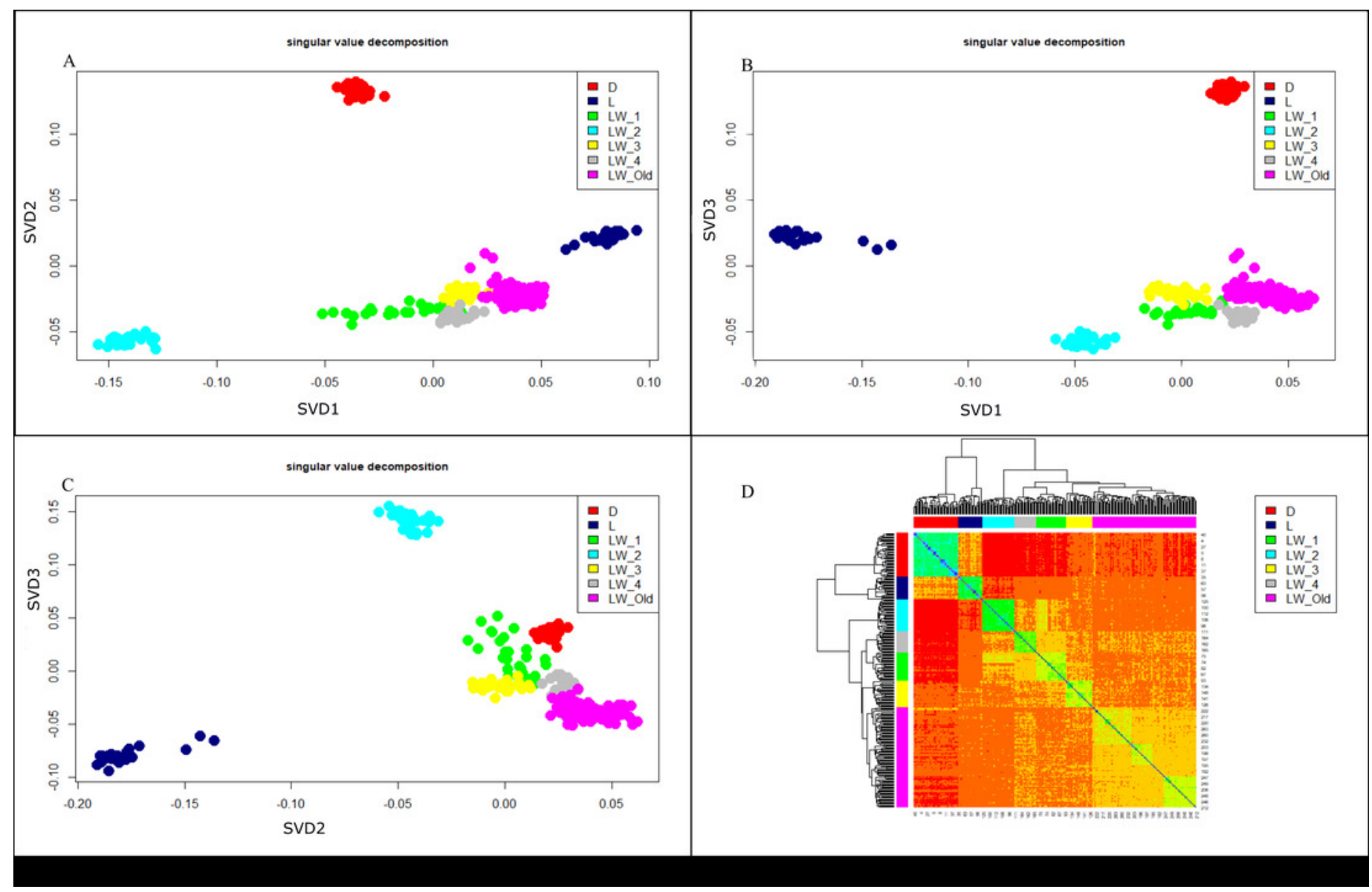


Figure 4

Figure 4. Manhattan plot LW_OLD vs. LW_NEW based on $F_{L K}$ results

According to the $F_{L K}$ method with the most significant signals, 185 SNPs were identified, of which 2 SNPs localized in chr4: 82530260-83269208 and 27 SNPs in chr6:

107577819-12095419 were also determined by the $F_{\text {ST }}$ method.

Manhattan plot: flk LW_Old vs LW_New

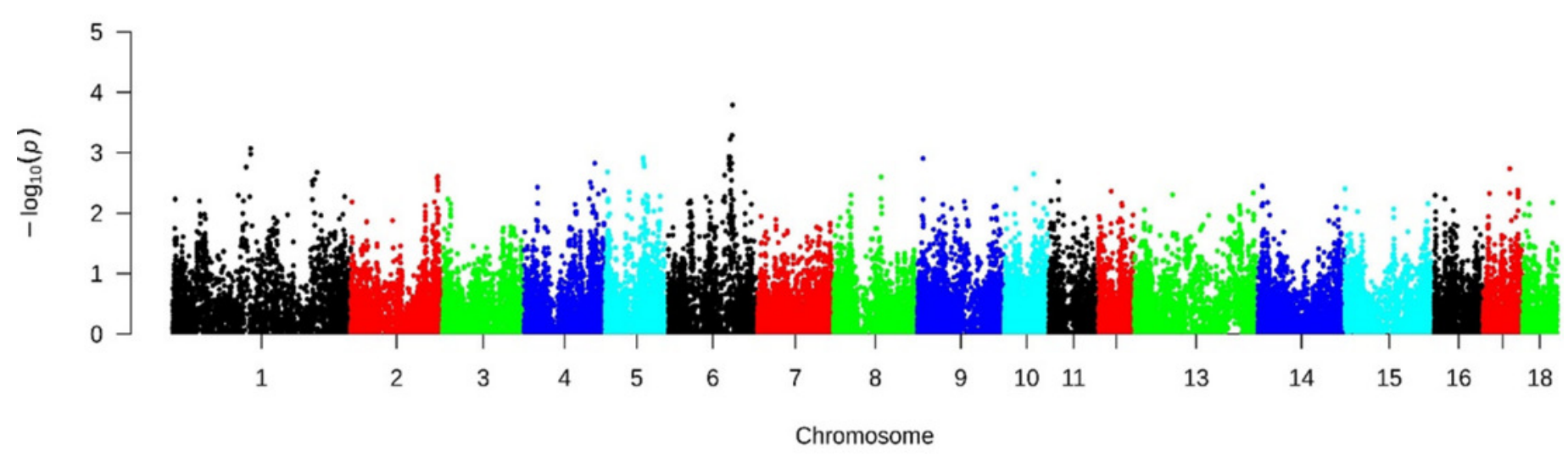

